\title{
Recent Developments on Rare-Earth Hexaboride Nanowires
}

\author{
Zhen Wang ${ }^{1}$ and Wei Han ${ }^{2, *(1)}$ \\ 1 School of Microelectronics, Southern University of Science and Technology, Shenzhen 518055, China; \\ wangz8@sustech.edu.cn \\ 2 Department of Applied Physics, The Hong Kong Polytechnic University, Kowloon, Hong Kong 999077, China \\ * Correspondence: weihan@polyu.edu.hk
}

check for

updates

Citation: Wang, Z.; Han, W. Recent Developments on Rare-Earth Hexaboride Nanowires. Sustainability 2021, 13, 13970. https://doi.org/ $10.3390 /$ su132413970

Academic Editor: Changhyun Roh

Received: 22 November 2021

Accepted: 14 December 2021

Published: 17 December 2021

Publisher's Note: MDPI stays neutral with regard to jurisdictional claims in published maps and institutional affiliations.

Copyright: (c) 2021 by the authors. Licensee MDPI, Basel, Switzerland. This article is an open access article distributed under the terms and conditions of the Creative Commons Attribution (CC BY) license (https:/ / creativecommons.org/licenses/by/ $4.0 /)$.

\begin{abstract}
With the rise of topological insulator samarium hexaboride $\left(\mathrm{SmB}_{6}\right)$, rare-earth hexaboride $\left(\mathrm{RB}_{6}\right)$ nanowires are the focus of the second wave of a research boom. Recent research has focused on new preparation methods, novel electronic properties, and extensive applications. Here, we review the recent developments in $\mathrm{RB}_{6}$ nanowires in the past five years. Two main synthesis methods (chemical vapor deposition and high-pressure solid-state) of $\mathrm{RB}_{6}$ nanowires are introduced and compared. Moreover, their electronic transport, magnetic properties, and superconducting properties are revealed. Furthermore, the applications of $\mathrm{RB}_{6}$ nanowires are presented, including as field emitters, photodetectors, and in energy storage. Finally, we detail further research directions for $\mathrm{RB}_{6}$ nanowires.
\end{abstract}

Keywords: rare-earth hexaboride; nanowire; field emission; chemical vapor deposition

\section{Introduction}

Rare-earth hexaborides $\left(\mathrm{RB}_{6}\right)$ have received substantial attention thanks to their high electrical conductivity, high melting points, and high chemical stability. Meanwhile, the strong correlation effect of $4 \mathrm{f}-5 \mathrm{~d}$ electrons of rare-earth elements also brings some newfangled physical properties of $\mathrm{RB}_{6}$ [1-3]. For example, yttrium hexaboride $\left(\mathrm{YB}_{6}\right)$ is a superconductor with a Tc of $7.2 \mathrm{~K}$, which is the second highest transition temperature among all borides [4]. Moreover, lanthanum hexaboride $\left(\mathrm{LaB}_{6}\right)$, possessing low work function of $2.7 \mathrm{eV}$, is a famous thermionic electron emission material with high current density and stability [5]. Cerium hexaboride $\left(\mathrm{CeB}_{6}\right)$ is an antiferromagnetic heavy-fermion metal, but recently, it was found to demonstrate low-energy ferromagnetic fluctuation [6]. Furthermore, as a ferromagnetic semimetal, europium hexaboride $\left(\mathrm{EuB}_{6}\right)$ recently exhibited a colossal magnetoresistance effect [7]. In recent years, the emergent topological insulator has increased interest in samarium hexaboride $\left(\mathrm{SmB}_{6}\right)$, which possesses both insulating bulk state and metallic surface state due to the inversion of the $\mathrm{d}$ and $\mathrm{f}$ bands. Experimental evidence proves that $\mathrm{SmB}_{6}$ is the first strongly correlated 3D topological Kondo insulator [8].

Due to the small size effect and quantum confinement effect, one-dimensional (1D) nanomaterials have new properties compared with bulk crystals. With the rise of 1D nanomaterials, $\mathrm{RB}_{6}$ experienced the first wave of a research boom from 2005 to 2015, and many $\mathrm{RB}_{6}$ nanowires were prepared by chemical vapor deposition (CVD) [9-20]. These $\mathrm{RB}_{6}$ nanowires achieved excellent field emission properties and mechanical properties [21-29]. From 2016, the second wave of research boom of $\mathrm{RB}_{6}$ began as $\mathrm{SmB}_{6}$ proved to be a topological insulator, and researchers began to explore the difference in topological properties between nanowires and bulk single crystals [8].

In this review, we summarize the recent developments in $\mathrm{RB}_{6}$ nanowires. Two main synthesis methods of $\mathrm{RB}_{6}$ nanowires are summarized. Furthermore, their electronic transport and magnetic properties are summarized. Finally, the applications of $\mathrm{RB}_{6}$ nanowires are presented, including as field emitters, photodetectors, and in energy storage. 


\section{Growth of $R B_{6}$ Nanowires}

The structural models of rare-earth hexaborides are shown in Figure $1 \mathrm{a} . \mathrm{RB}_{6}$ crystals are $\mathrm{CsCl}$-type structures with a space group of $\mathrm{Pm}-3 m$. Among 17 rare-earth elements, only 13 can form hexaborides with boron, which are $\mathrm{YB}_{6}, \mathrm{LaB}_{6}, \mathrm{CeB}_{6}, \mathrm{PrB}_{6}, \mathrm{NdB}_{6}, \mathrm{SmB}_{6}, \mathrm{EuB}_{6}$, $\mathrm{GdB}_{6}, \mathrm{TbB}_{6}, \mathrm{DyB}_{6}, \mathrm{HoB}_{6}, \mathrm{ErB}_{6}$, and $\mathrm{YbB}_{6}$. On the left side of Figure $1 \mathrm{a}$, one $\mathrm{B}_{6}$ octahedron is surrounded by eight $R$ atoms, and $R_{6}$ crystals generally have suitable conductivity. On the right side of Figure $1 \mathrm{a}$, one $\mathrm{R}$ atom is encircled by eight $\mathrm{B}_{6}$ octahedra, and $\mathrm{B}_{6}$ octahedra are connected by covalent bonds, which give $\mathrm{RB}_{6}$ high melting points, high hardness, and high chemical stability. From the study of electronic structure and bonding characteristics of $\mathrm{LaB}_{6}$, lanthanum and adjacent boron atoms are not sufficiently bonded, indicating that lanthanum atoms can migrate efficiently [30]. During the thermal field emission, the lanthanum atoms can freely migrate in the boron frame to replace the lanthanum atoms evaporated on the surface, thus showing excellent field emission performance [31]. Rareearth hexaborides share common properties, but the special electronic structure of each material determines their characteristic properties. For instance, $\mathrm{YbB}_{6}$ was once proposed to be a topological insulator, but new evidence for the electronic structure suggests that its electronic states originate from the hybridization of the $\mathrm{Yb} \mathrm{d}$ - and $\mathrm{B}$ p-orbits. This indicates that $\mathrm{YbB}_{6}$ has a non-topological insulator electronic structure [32]. Although most of the $\mathrm{RB}_{6}$ crystals are metals, $\mathrm{SmB}_{6}$ can open the band gap at low temperature due to the hybridization of the $4 \mathrm{f}$ bands and $5 \mathrm{~d}$ bands, and meanwhile, metallic surface states are topologically protected [33]. To study and utilize the properties of $\mathrm{RB}_{6}$, high-quality crystals, especially low-dimensional nanowires, need to be prepared. Concerning materials preparation, only two methods are reported to obtain $\mathrm{RB}_{6}$ nanowires, chemical vapor deposition (CVD) and high-pressure solid-state (HPSS), as depicted in Figure 1b. CVD is a tradition method to grow $\mathrm{RB}_{6}$ nanowires using vapor-liquid-solid (VLS) or vapor-solid (VS) mechanisms at a high temperature. HPSS using autoclave is a new method to grow $\mathrm{RB}_{6}$ nanowires at a low temperature.

a
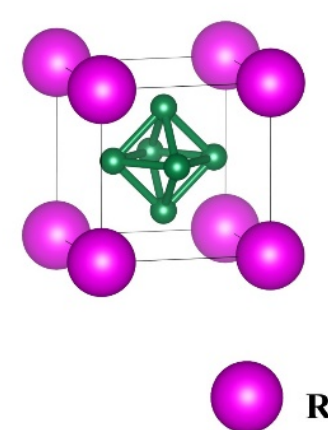

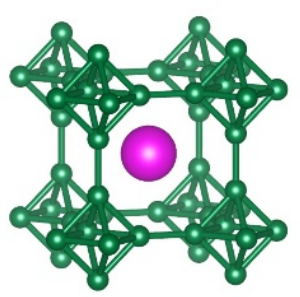

$\odot$ B

\section{R = Y, La, Ce, Pr, Nd, Sm, Eu, Gd, Tb, Dy, Ho, Er, Yb}

b

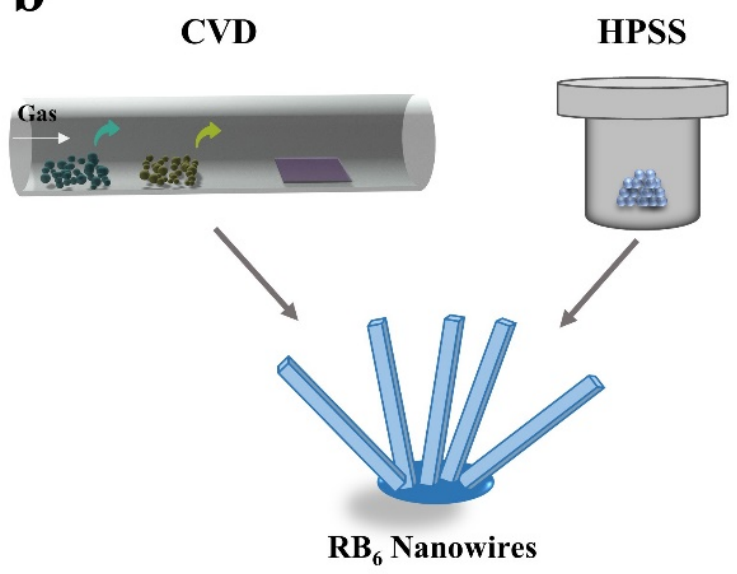

Figure 1. (a) The ball-and-stick structural models of rare-earth hexaborides. (b) Sketch map of two growth methods of $\mathrm{RB}_{6}$ nanowires.

\subsection{CVD Growth}

In the past 5 years, a series of $\mathrm{RB}_{6}$ nanowires were prepared by the CVD method, namely, $\mathrm{LaB}_{6}, \mathrm{CeB}_{6}, \mathrm{NdB}_{6}, \mathrm{SmB}_{6}$, and ternary $\mathrm{La}_{x} \mathrm{Pr}_{1-\mathrm{x}} \mathrm{B}_{6}$ nanowires, as shown in Figure 2 . Different methods use different source materials and substrates, as summarized below.

$$
\mathrm{RCl}_{3}+\mathrm{B}+\mathrm{B}_{2} \mathrm{O}_{3}+\mathrm{H}_{2} \rightarrow \mathrm{RB}_{6}(\mathrm{R}=\mathrm{La}, \mathrm{Sm})
$$



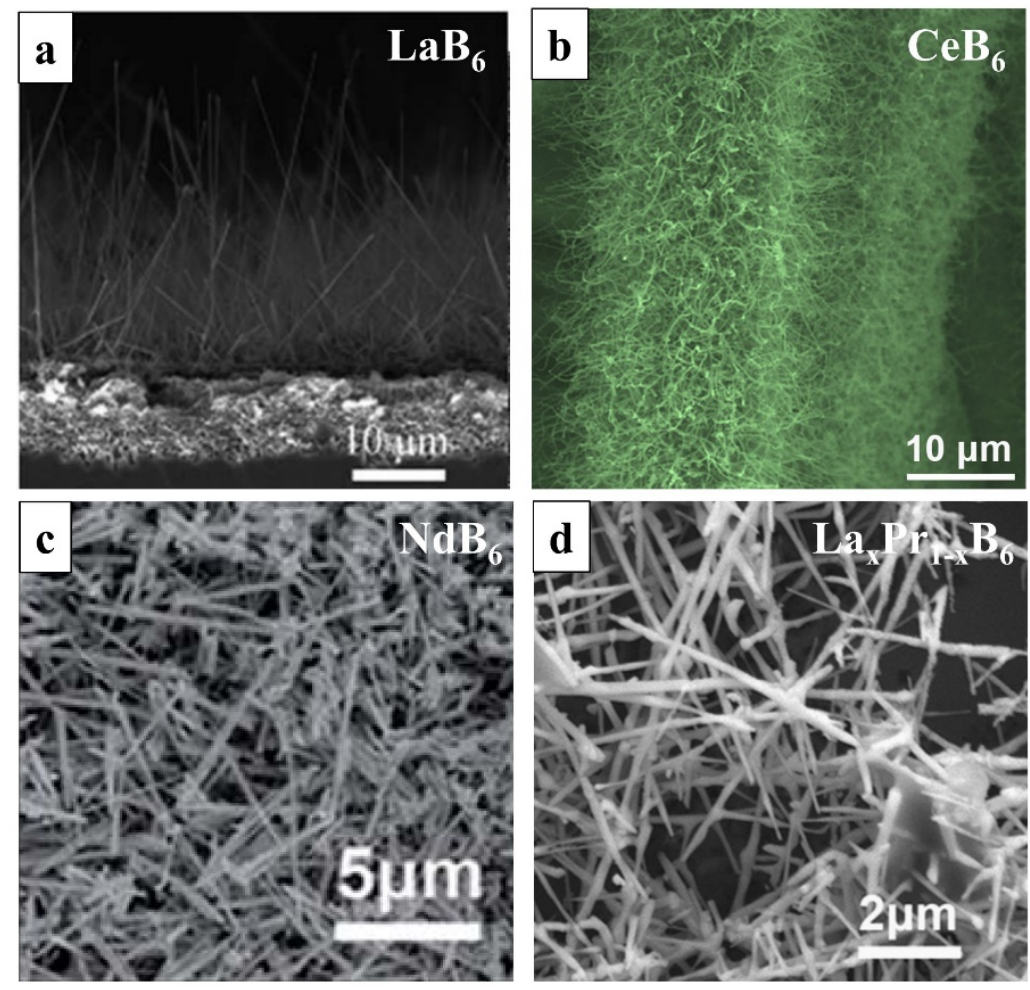

Figure 2. SEM images of (a) CVD-grown $\mathrm{LaB}_{6}$ nanowires [34] (Copyright 2017, The Royal Society of Chemistry), (b) $\mathrm{CeB}_{6}$ nanowires [35] (Copyright 2017, Elsevier Science B.V.), (c) $\mathrm{NdB}_{6}$ nanowires [36] (Copyright 2016, The Royal Society of Chemistry), (d) $\mathrm{La}_{x} \mathrm{Pr}_{1-\mathrm{x}} \mathrm{B}_{6}$ nanowires [37] (Copyright 2016, Elsevier Science B.V.).

From 2017 to 2019, Gan et al. used a Ni-catalyzed low-pressure CVD method to prepare high-quality $\mathrm{LaB}_{6}$ and $\mathrm{SmB}_{6}$ nanowires with a length of tens of microns, as depicted in Figure 2a [34,38]. The source materials of this method are $\mathrm{LaCl}_{3}\left(\mathrm{SmCl}_{3}\right), \mathrm{H}_{2}, \mathrm{~B}$, and $\mathrm{B}_{2} \mathrm{O}_{3}$, and they are non-toxic. Halides are common rare-earth sources, easy to decompose and reactive. The innovation of this method lies in the use of $\mathrm{B}$ and $\mathrm{B}_{2} \mathrm{O}_{3}$ as the boron source, because boron powder alone is extremely difficult to change to a gaseous state and has low reactivity. At a high temperature of $1000{ }^{\circ} \mathrm{C}$, the mixture of $\mathrm{B}$ and $\mathrm{B}_{2} \mathrm{O}_{3}$ can produce active $\mathrm{B}_{2} \mathrm{O}_{2}$ vapor, and then $\mathrm{B}_{2} \mathrm{O}_{2}$ reacts with $\mathrm{LaCl}_{3}\left(\mathrm{SmCl}_{3}\right)$ and $\mathrm{H}_{2}$ to grow $\mathrm{LaB}_{6}$ and $\mathrm{SmB}_{6}$ nanowires on Ni-coated $\mathrm{Si}$ substrates. The $\mathrm{LaB}_{6}$ nanowires exhibit excellent field emission properties and stability, both at room temperature and at high temperatures [34]. Compared with bulk single crystals, the transport properties prove that $\mathrm{SmB}_{6}$ nanowires have less residual resistance due to their large surface area [38].

$$
\mathrm{CeCl}_{3} \cdot 7 \mathrm{H}_{2} \mathrm{O}+\mathrm{B}_{2} \mathrm{H}_{6} \rightarrow \mathrm{CeB}_{6}
$$

In another method, $\mathrm{Fu}$ et al. applied a low-pressure $\mathrm{CVD}$ route to grow $\mathrm{CeB}_{6}$ nanowires on Au-coated flexible carbon cloths using $\mathrm{CeCl}_{3} \cdot 7 \mathrm{H}_{2} \mathrm{O}$ and $\mathrm{B}_{2} \mathrm{H}_{6}$ as source materials, as depicted in Figure $2 \mathrm{~b}$ [35]. In this method, the $\mathrm{CeCl}_{3} \cdot 7 \mathrm{H}_{2} \mathrm{O}$ is safe, but the $\mathrm{B}_{2} \mathrm{H}_{6}$ gas is deleterious to humans. The field emission properties of flexible $\mathrm{CeB}_{6}$ nanowire arrays are outstanding, showing a low turn-on field and a high field emission enhancement factor. Meanwhile, the field current density can remain stable under bending conditions.

$$
\mathrm{SmCl}_{3}+\mathrm{BCl}_{3}+\mathrm{H}_{2} \rightarrow \mathrm{SmB}_{6}
$$

Besides $\mathrm{B}_{2} \mathrm{H}_{6}$ gas, $\mathrm{BCl}_{3}$ gas is also a common source of gaseous boron. In 2016, Zhou et al. used a CVD route to grow $\mathrm{SmB}_{6}$ nanowires on Au-coated Si substrates [39]. The electron transport testing on four-probe single-nanowire devices showed that the $\mathrm{SmB}_{6}$ 
nanowire has a saturated resistance under $10 \mathrm{~K}$ due to the presence of both insulating state in bulk and conductive state on the surface.

$$
\mathrm{R}+\mathrm{BCl}_{3}+\mathrm{H}_{2} \rightarrow \mathrm{RB}_{6}\left(\mathrm{R}=\mathrm{Nd}, \mathrm{La}_{\mathrm{x}} \mathrm{Pr}_{1-\mathrm{x}}\right)
$$

In addition to the catalytic growth using metal particles $(\mathrm{Au}, \mathrm{Ni})$, there is also selfcatalytic growth using rare-earth metals themselves as catalysts. In 2016, Han et al. reported the self-catalytic growth of $\mathrm{NdB}_{6}$ and ternary $\mathrm{La}_{\mathrm{x}} \mathrm{Pr}_{1-\mathrm{x}} \mathrm{B}_{6}$ nanowires by an ordinarypressure CVD method, as shown in Figure 2c,d [36,37]. Besides the $\mathrm{NdB}_{6}$ nanowires, they also acquired $\mathrm{NdB}_{6}$ nanoawls and nanotubes. The growth of ternary $\operatorname{La}_{x} \operatorname{Pr}_{1-x} \mathrm{~B}_{6}$ nanowires reveals that this self-catalytic method is suitable for doping and preparation of $\mathrm{RB}_{6}$ alloys.

\subsection{HPSS Growth}

Along with the CVD route, the solid-state method is also a route to prepare $\mathrm{RB}_{6}$ crystals, including the high-pressure solid-state method [40-47], solution combustion method [48,49], and molten salt method [50,51]. However, because the diffusion rate of atoms in solid-state materials is extremely slow, it is difficult to obtain the nanowire morphology. At the same time, the low reactivity of solid source materials is also a problem restricting the development of $1 \mathrm{D} \mathrm{RB} 6$ nanomaterials. To solve such problems, from 2016, Zhao group utilized a rare-earth metal, self-catalytic, high-pressure solid-state method (HPSS) route to prepare various $\mathrm{RB}_{6}$ nanowires, as shown in Figure 3a-f [52-57]. It is noteworthy that, until now, this is the only report on the synthesis of $\mathrm{YbB}_{6}$ nanowires [56]. The general chemical reaction of the HPSS method is given below.

$$
\mathrm{R}+6 \mathrm{H}_{3} \mathrm{BO}_{3}+10 \mathrm{Mg}+\mathrm{I}_{2} \rightarrow \mathrm{RB}_{6}+9 \mathrm{MgO}+\mathrm{MgI}_{2}+9 \mathrm{H}_{2} \mathrm{O}
$$
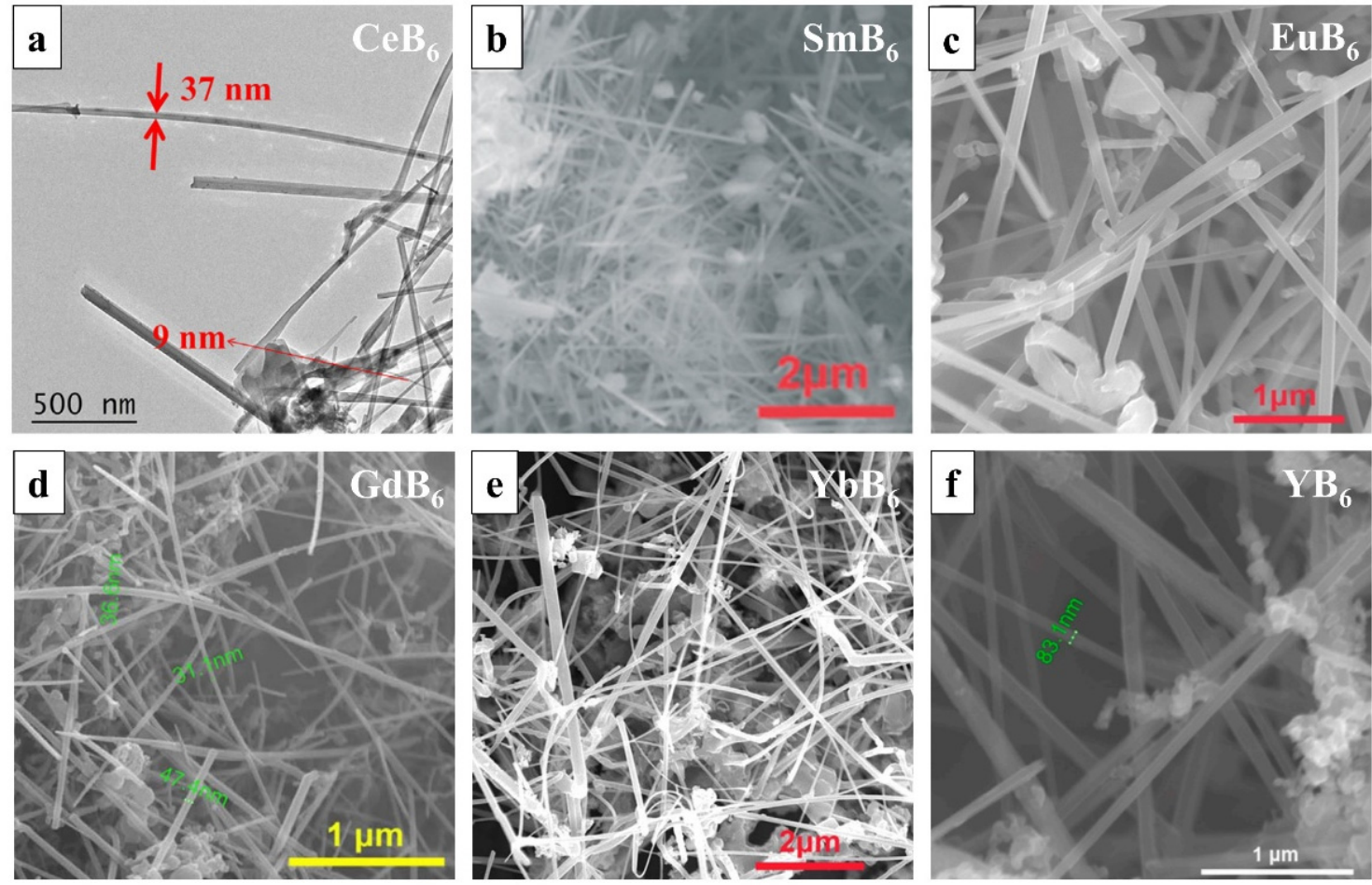

Figure 3. (a) TEM image of $\mathrm{CeB}_{6}$ nanowires grown by HPSS method [52] (Copyright 2020, Elsevier Science B.V.). (b) SEM images of HPSS-grown $\mathrm{SmB}_{6}$ nanowires [53] (Copyright 2016, The Royal Society of Chemistry). (c) EuB 6 nanowires [54] (Copyright 2021, Wiley-VCH GmbH). (d) $\mathrm{GdB}_{6}$ nanowires [55] (Copyright 2017, Elsevier Science B.V.). (e) $\mathrm{YbB}_{6}$ nanowires [56] (Copyright 2018, Elsevier Science B.V.). (f) YB 6 nanowires [57] (Copyright 2021, Elsevier Science B.V.).

In this equation, $\mathrm{Mg}$ is used for the reduction of $\mathrm{H}_{3} \mathrm{BO}_{3}$, and $\mathrm{I}_{2}$ acts as the catalyst to boost the reaction of $\mathrm{R}$ and $\mathrm{B}$ atoms. From the literature, the Gibbs free energy $\left(\Delta_{\mathrm{r}} \mathrm{G}\right)$ 
and heat function $\left(\Delta_{\mathrm{r}} \mathrm{H}\right)$ of this equation are about $-1900 \mathrm{~kJ} \mathrm{~mol}^{-1}$ and $-2000 \mathrm{~kJ} \mathrm{~mol}^{-1}$, respectively, demonstrating that the reaction is spontaneous and exothermic. Moreover, the high pressure in the autoclave is generated by iodine (higher than $45 \mathrm{~atm}$ ), which is also a key to obtaining $\mathrm{RB}_{6}$ nanowires. Due to high exothermic and high pressure, the trigger temperature of this HPSS method $\left(200-260^{\circ} \mathrm{C}\right)$ is generally much lower than that of the CVD method $\left(950-1100{ }^{\circ} \mathrm{C}\right)$. From the ex situ time-dependent morphology study (5 $\mathrm{min}, 30 \mathrm{~min}, 360 \mathrm{~min}$ ), we speculate that the growth of nanowires has three steps: (i) diffusion and reaction of $\mathrm{R}$ and $\mathrm{B}$ atoms; (ii) nucleation of $\mathrm{RB}_{6}$ crystals; (iii) growth of $\mathrm{RB}_{6}$ nanowires [53]. This HPSS route is a general method for the synthesis of rareearth hexaborides, which we believe can be extended to the synthesis of other metal boride nanowires.

\section{Properties and Applications of $\mathrm{RB}_{6}$ Nanowires}

\subsection{Electronic Transportation}

As an emerging topological insulator, many experiments and theoretical studies have been conducted on bulk $\mathrm{SmB}_{6}$ single crystals [8]. From 2016, researchers began to investigate the novel electronic transport and magneto-transport properties of $\mathrm{SmB}_{6}$ nanowires [37,38,53,58-62]. In 2017, Kong et al. reported the spin-polarized surface state transport of single $\mathrm{SmB}_{6}$ nanowires (Figure $4 \mathrm{a}-\mathrm{c}$ ) [58]. Under $5 \mathrm{~K}$, the resistance appears saturated and flat, indicating that the surface states control the transport behavior. The appearance of topological surface states is caused by the reversal of $d$ and $f$ electrons. The fitting of a temperature-dependent resistance curve reveals that $\mathrm{SmB}_{6}$ nanowire has a bulk gap $\sim 3.2 \mathrm{meV}$, which is opened by the hybridization of the $4 f$ bands and $5 d$ bands in $\mathrm{SmB}_{6}$ nanowires. As shown in Figure $4 c$, the magnetoresistance (MR) of $\mathrm{SmB}_{6}$ nanowires is negative and the MR shows no sign of saturation at high magnetic field up to $14 \mathrm{~T}$. The negative MR indicates that this transport behavior is spin-dependent. Furthermore, the nonlocal tests reveal that the surface state transport of $\mathrm{SmB}_{6}$ nanowires is spin-polarized. In another interesting work, Zhou et al. reported the positive planar Hall effect (PHE) of $\mathrm{SmB}_{6}$ nanowires (Figure $4 \mathrm{~d}-\mathrm{f}$ ) [59]. They found that as the temperature decreases, the amplitude increases sharply, but saturates at $5 \mathrm{~K}$. This positive PHE is due to the surface states of $\mathrm{SmB}_{6}$. In other studies, the researchers found the anomalous magnetoresistance and the hysteresis of magnetoresistance in $\mathrm{SmB}_{6}$ nanowires [60-62].

In the $\mathrm{RB}_{6}$ family, like $\mathrm{SmB}_{6}, \mathrm{YbB}_{6}$ is proposed to be a mixed-valent $\left(\mathrm{Yb}^{2+} / \mathrm{Yb}^{3+}\right)$ topological insulator and demonstrates new quantum phenomena [63-65]. In 2018, Han et al. reported the semiconductor-insulator transition behavior in a $\mathrm{YbB}_{6}$ nanowire (Figure 5) [55]. As shown in Figure 5b, as the temperature decreases from 300 to $2 \mathrm{~K}$, the resistivity of the $\mathrm{YbB}_{6}$ nanowire device undergoes a dramatic 49 -fold increase $\left(\rho_{2} \mathrm{~K} / \rho_{300 \mathrm{~K}}=49\right)$. They propose that the semiconductor-insulator transition is due to a small band gap opening at a low temperature induced by the slightly boron-rich or boron-deficient segments in $\mathrm{YbB}_{6}$ nanowires. Furthermore, the magnetoresistance (MR) of the $\mathrm{YbB}_{6}$ nanowire was tested with perpendicular magnetic field $\mathrm{B}=0-7 \mathrm{~T}$ at various temperatures. As displayed in Figure 5c, the MR shows no sign of saturation at high magnetic field up to $14 \mathrm{~T}$ and has a linear dependence with $\mathrm{B}^{2}$ at $2 \mathrm{~K}$ and $10 \mathrm{~K}$, which follows Kohler's law. Because a semiconductor-insulator transition occurred at $2 \mathrm{~K}$ for $\mathrm{YbB}_{6}$ nanowires, the hole-dominant transport is credible at $2 \mathrm{~K}$ and the transport at $10 \mathrm{~K}$ is electron-dominant.

Of all the metal borides, $\mathrm{YB}_{6}$ bulk crystals have the second highest superconducting transition temperature of $7.2 \mathrm{~K}$ after $\mathrm{MgB}_{2}$. More superconducting properties have been studied in bulk $\mathrm{YB}_{6}$ single crystals, but the superconducting properties of $\mathrm{YB}_{6}$ nanowires have not been reported. Recently, Wang et al. reported the synthesis of $1 \mathrm{D} \mathrm{YB}_{6}$ nanowires by a high-pressure solid-state method and studied their magnetic properties (Figure 6). The temperature-dependent magnetization under zero-field cooling and field cooling revealed that the $\mathrm{YB}_{6}$ nanowires have a superconducting transition with $\mathrm{T}_{\mathrm{c}}=7.8 \mathrm{~K}$. Meanwhile, they found that the $\mathrm{YB}_{6}$ nanowires exhibited a peak effect in the superconducting state 
observed from the magnetic hysteresis loops obtained at $2 \mathrm{~K}$ and $10 \mathrm{~K}$, indicating that $\mathrm{YB}_{6}$ nanowires pertain to a type-II superconductor.
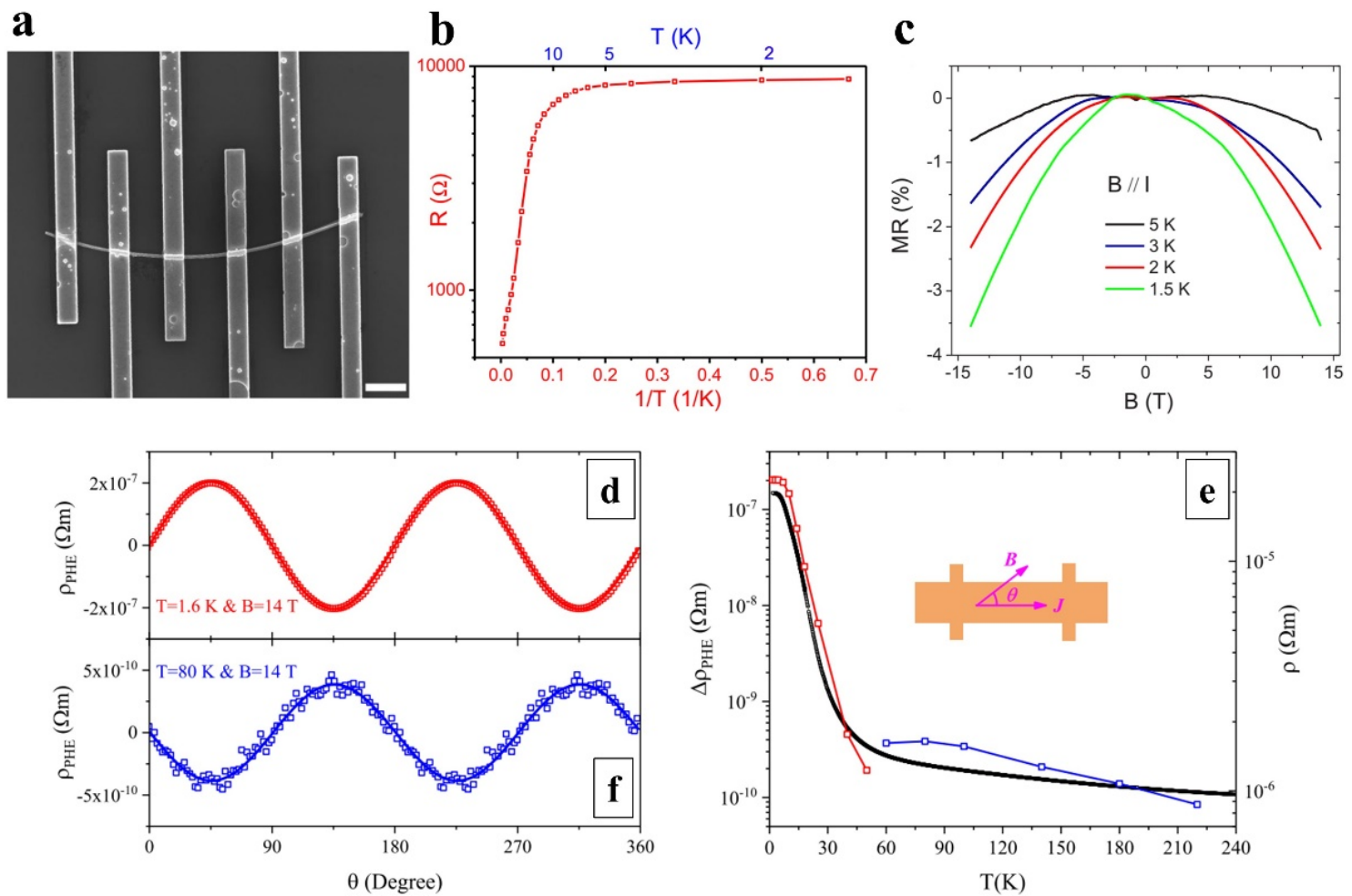

Figure 4. (a) SEM image of $\mathrm{A} \mathrm{SmB}_{6}$ nanowire device, the scalebar is $2 \mu \mathrm{m}$. (b) Temperature-dependent resistance of the $\mathrm{SmB}_{6}$ nanowire. (c) Magnetoresistance curves under a parallel magnetic field at various temperatures [58]. Copyright 2017, American Physical Society. (d) Planar Hall resistivity with various angles at 1.6 K. (e) PHE amplitude and resistivity. Inset is the definition of tilting angle $\theta$. (f) Planar Hall resistivity with various angles at $80 \mathrm{~K}$ [59]. Copyright 2019, American Physical Society.
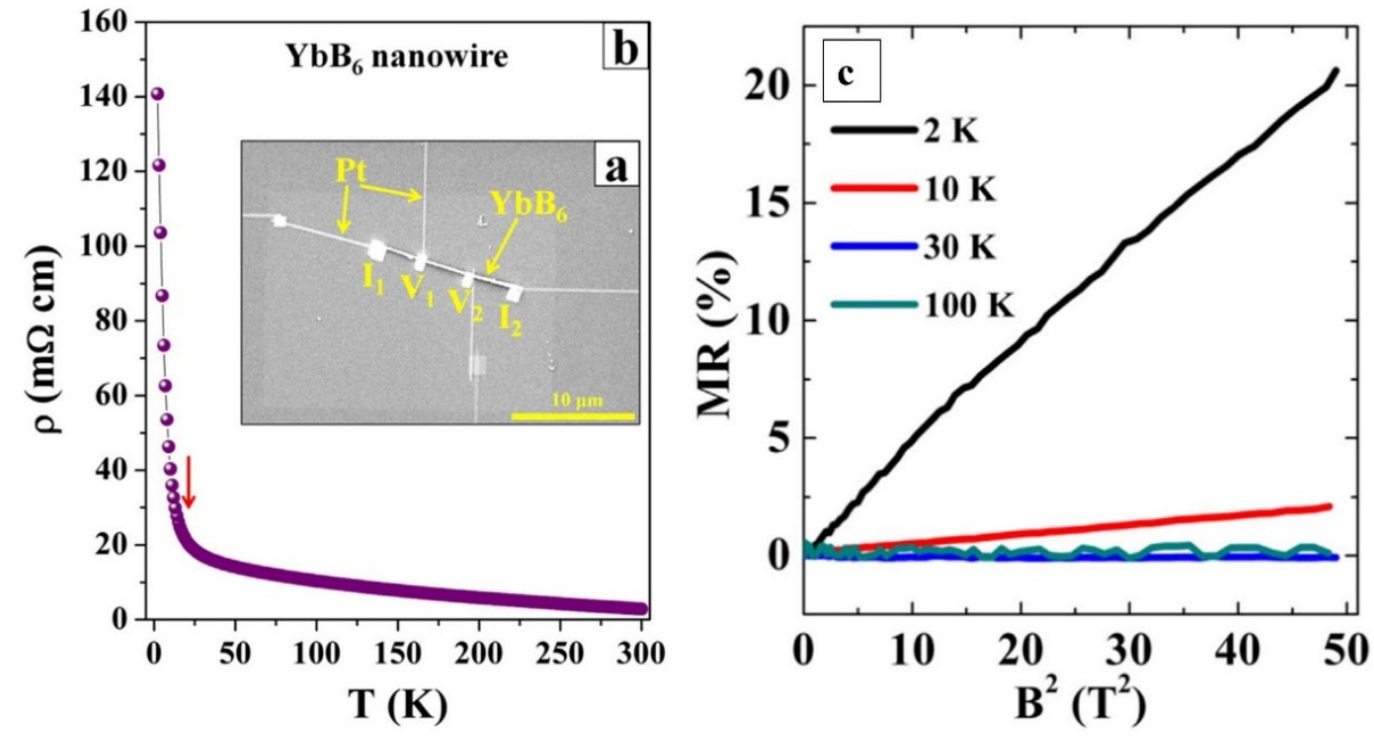

Figure 5. (a) SEM image of the $\mathrm{YbB}_{6}$ nanowire device. (b) Resistivity as a function of temperature from 2 to $300 \mathrm{~K}$. (c) Magnetoresistance (MR) as a function of $\mathrm{B}^{2}$ at various temperatures [55]. Copyright 2018, Elsevier Science B.V. 

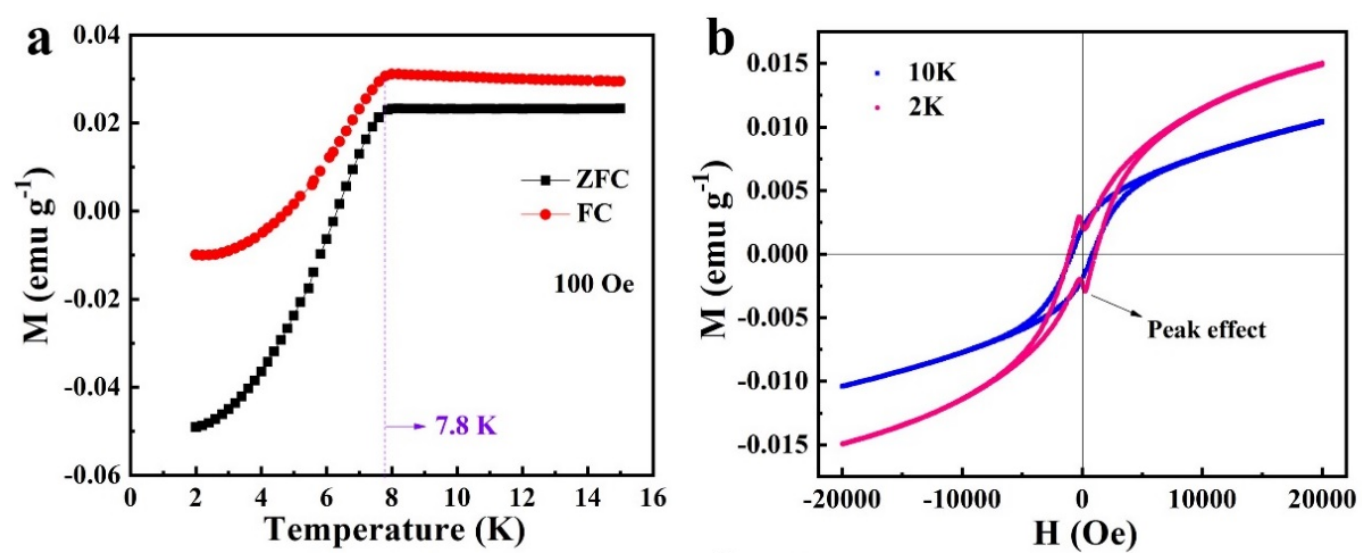

Figure 6. (a) The temperature-dependent magnetization under zero-field cooling and field cooling modes of superconducting $\mathrm{YB}_{6}$ nanostructure. (b) The magnetic hysteresis loops obtained at $2 \mathrm{~K}$ and 10 K [57]. Copyright 2021, Elsevier Science B.V.

$\mathrm{LaB}_{6}$ bulk single crystals have been applied in commercial scanning electron microscopy and transmission electron microscopy. For $\mathrm{RB}_{6}$ nanowires, the most attractive application is also the field emitter of an electronic gun of an electron microscope (Figure 7) [66-68]. Published in Nature Nanotechnology, Zhang et al. reported the first application of a single $\mathrm{LaB}_{6}$ nanowire to scanning electron microscopy, revealing excellent performance [66]. Their $\mathrm{LaB}_{6}$ nanowire electron source shows low work function, is chemically inert, and has high monochromaticity. When assembled into a field-emission gun of SEM, it demonstrates ultra-low emission decay, and its current density gain is three orders of magnitude higher than traditional $\mathrm{W}$ tips. By this $\mathrm{LaB}_{6}$ nanowire-based SEM, they obtained low-noise and high-resolution images, better than W-tip-based SEM. Recently, published in Nature Nanotechnology in 2021, Zhang et al. reported the installation of a single $\mathrm{LaB}_{6}$ nanowire into an aberration-corrected transmission electron microscope [67]. The $\mathrm{LaB}_{6} \mathrm{NW}$-based TEM achieved atomic resolution and probe-forming modes at $60 \mathrm{kV}$ energy. Compared with the state-of-the-art W (310) electron source, the nanostructured electron source provides higher temporal coherence at a spatial frequency of $105 \mathrm{pm}$, showing a higher contrast transfer amplitude of $84 \%$ and a spectral energy resolution of $35 \%$. The first demonstration of the $\mathrm{LaB}_{6}$ nanowire electron source in SEM and TEM reveals that the $\mathrm{RB}_{6}$ nanowires have notable application prospects and commercial value both in electron microscopy and other electron-emitting devices.
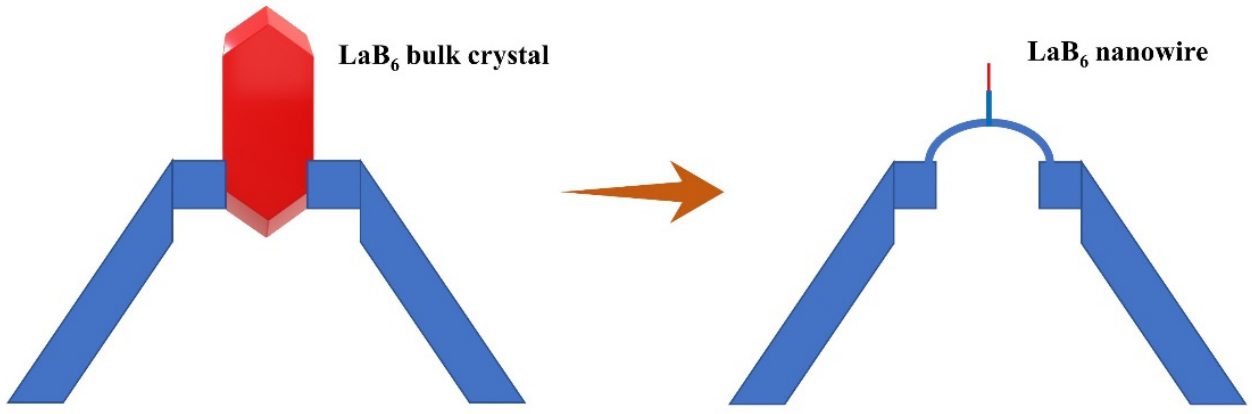

Figure 7. Illustrations of the $\mathrm{LaB}_{6}$ bulk crystal and nanowire electron-emission sources in electron microscopy.

\subsection{Optoelectronic Properties}

Most of the $\mathrm{RB}_{6}$ crystals are metals with zero band gap, and thus, they are not suitable for semiconductor devices, such as field effect transistors and photodetectors. However, as a topological Kondo insulator, $\mathrm{SmB}_{6}$ shows a small gap ( $\left.3 \mathrm{meV}\right)$, evidenced by electrical transport measurements, and may have potential in fabricating devices. Recently, 
Zhou et al. [69] first reported the self-powered $\mathrm{SmB}_{6}$ nanowire photodetectors with broadband wavelengths covering from $488 \mathrm{~nm}$ to $10.6 \mu \mathrm{m}$ (Figure 8). They claimed that the photocurrent stemmed from the interface of $\mathrm{SmB}_{6}$ nanowire and Au electrodes owing to the built-in potential, proved by the spatially resolved photocurrent mapping. The current on/off ratio, responsibility, and specific detectivity are $100,1.99 \mathrm{~mA} / \mathrm{W}$, and $2.5 \times 10^{7}$ Jones, respectively. The demonstration of a $\mathrm{SmB}_{6}$ nanowire photodetector reveals its application potential in mid-infrared photodetectors.
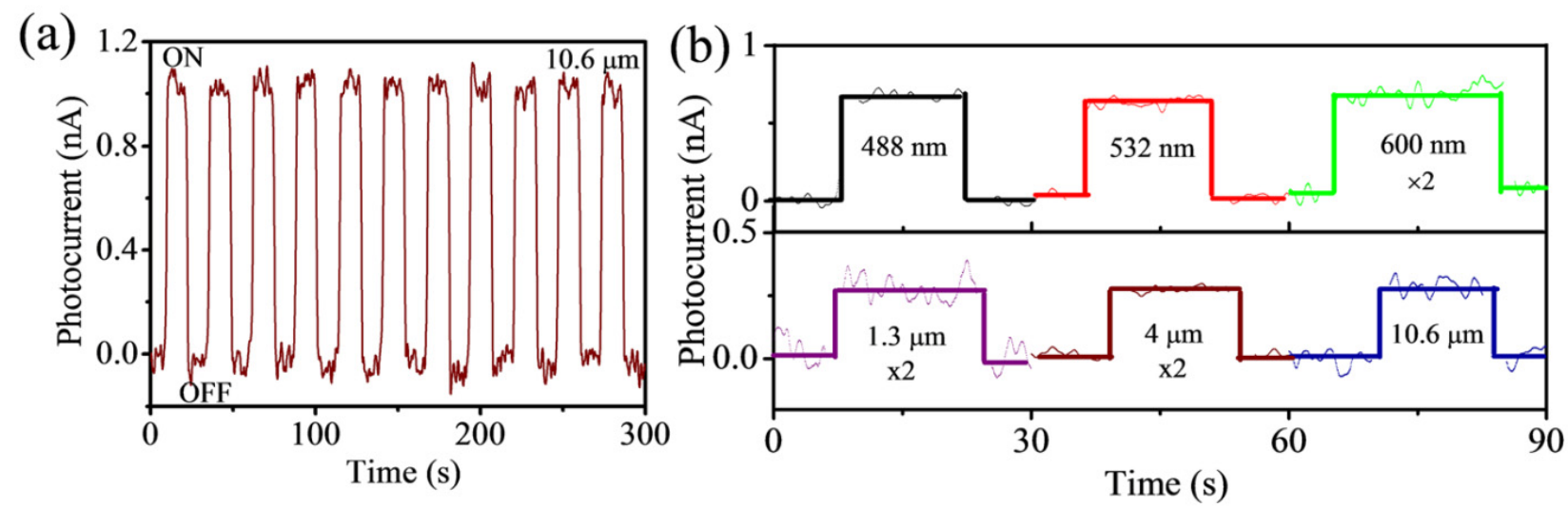

Figure 8. (a) Current-time measurement of $\mathrm{SmB}_{6}$ nanowire photodetector under illuminating of $10.6 \mu \mathrm{m}$ light source. (b) Current-time curves of $\mathrm{SmB}_{6}$ nanowire photodetector under illuminating with different light wavelengths [69]. Copyright 2018, AIP Publishing.

\subsection{Electrochemical Performances}

$\mathrm{RB}_{6}$ crystals show excellent metal-like conductivity $\left(>10^{3} \mathrm{~S} \mathrm{~m}^{-1}\right)$ and they are suitable for active electrochemical electrode materials for energy storage. Recently, Wang et al. [52] reported the application of $\mathrm{CeB}_{6}$ nanowires as lithium-ion battery anode materials, and they obtained a capacity of $\sim 225 \mathrm{~mA} \mathrm{~h} \mathrm{~g}^{-1}$ after 60 cycles (Figure 9a). The kinetic analysis shows that the $\mathrm{Li}^{+}$storage mechanism mainly comes from the surface capacitive behavior. Xue et al. [70] reported the $\mathrm{LaB}_{6}$ nanowires on carbon fiber as electrode materials for supercapacitors (Figure $9 \mathrm{~b}$ ). The $\mathrm{LaB}_{6}$ electrode materials showed a high areal capacitance of $17.34 \mathrm{mF} \mathrm{cm}{ }^{-2}$ and revealed suitable cycling stability after 10,000 cycles. The successful application of $\mathrm{RB}_{6}$ nanowires in batteries and capacitors demonstrates their potential in the field of electrochemical energy storage.

$\mathbf{a}$

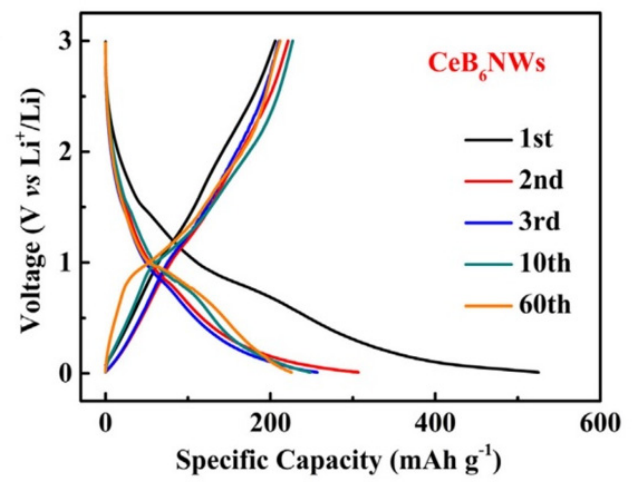

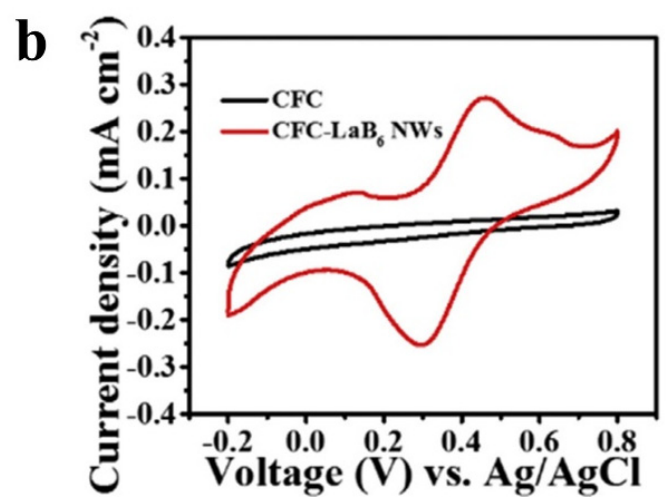

Figure 9. (a) The charge-discharge curves of $\mathrm{CeB}_{6}$ nanowire electrodes for lithium-ion battery anodes [52]. (Copyright 2020, Elsevier Science B.V.) (b) CV curves of CFC and $\mathrm{LaB}_{6}$-CFC electrode for supercapacitors [70]. (Copyright 2018, Elsevier Science B.V.)

\section{Conclusions and Outlook}

In conclusion, we review in this paper the recent developments in $\mathrm{RB}_{6}$ nanowires in the past five years. Two main synthesis methods (CVD and HPSS) of $\mathrm{RB}_{6}$ nanowires are 
outlined and compared. Moreover, their electronic transport, magnetic properties, and superconducting properties are summarized. Finally, the applications of $\mathrm{RB}_{6}$ nanowires are revealed, including as field electron emitters, photodetectors, and in energy storage.

With the rise of two-dimensional (2D) materials, $\mathrm{RB}_{6}$ nanowires should absorb some of the advantages of $2 \mathrm{D}$ material, such as atomically thin and large area lateral size. If $\mathrm{RB}_{6}$ nanowires become thinner and wider, also called $\mathrm{RB}_{6}$ nanobelts, they may reveal novel properties (Figure 10). In a recent study, Lee et al. reported the perfect Andreev reflection in a topological superconducting state based on $\mathrm{SmB}_{6} / \mathrm{YB}_{6}$ heterostructures [71]. We believe the heterostructures based on combinations of $\mathrm{RB}_{6}$ nanowires or films may find new physical phenomena and represent future trends. In terms of the synthesis methods, CVD, solid-state, MBE, and PLD methods are all applicable, and only few improvements are needed. For instance, when using the CVD method to grow $\mathrm{RB}_{6}$ nanobelts, mica substrates may be the best. Furthermore, adding some salts can improve the growth efficiency [72]. Meanwhile, 2D rare-earth materials have shown novel properties and applications, and thus, new discoveries and properties will also arise regarding the atomically thin $2 \mathrm{D} \mathrm{RB}_{6}$ nanobelts.

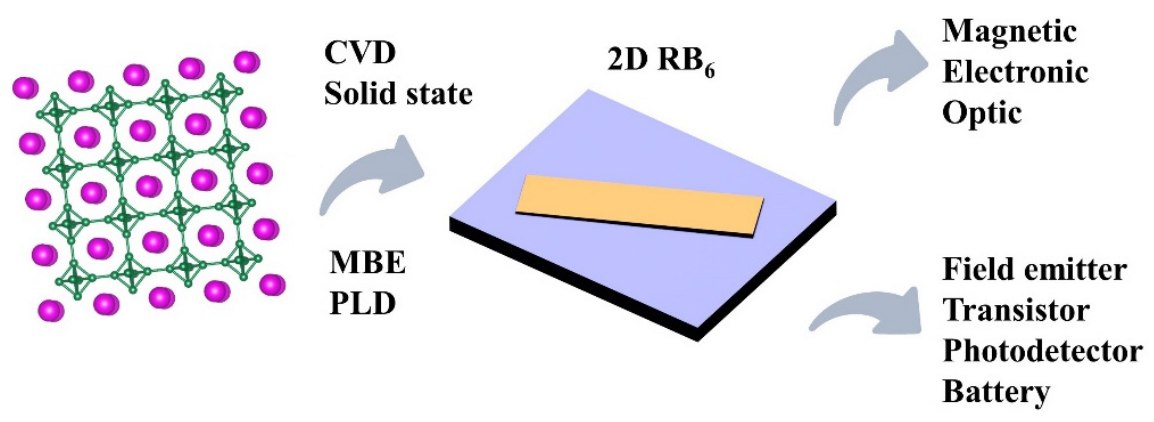

Figure 10. Outlook on the future growth, properties, and applications of $\mathrm{RB}_{6}$ nanostructures.

Author Contributions: Writing—original draft preparation, Z.W., W.H.; writing—review and editing, Z.W., W.H.; supervision, W.H.; funding acquisition, W.H. All authors have read and agreed to the published version of the manuscript.

Funding: This research was funded by National Natural Science Foundation Committee of China (grant number 22105162).

Acknowledgments: The authors thank the grant from National Natural Science Foundation Committee of China (grant number 22105162).

Conflicts of Interest: The authors declare no conflict of interest.

\section{References}

1. Ji, X.H.; Zhang, Q.Y.; Xu, J.Q.; Zhao, Y.M. Rare-earth hexaborides nanostructures: Recent advances in materials, characterization and investigations of physical properties. Prog. Solid State Chem. 2011, 39, 51-69. [CrossRef]

2. Carenco, S.; Portehault, D.; Boissiere, C.; Mezailles, N.; Sanchez, C. Nanoscaled metal borides and phosphides: Recent developments and perspectives. Chem. Rev. 2013, 113, 7981-8065. [CrossRef] [PubMed]

3. Gan, H.; Zhang, T.; Guo, Z.; Lin, H.; Li, Z.; Chen, H.; Chen, J.; Liu, F. The growth methods and field emission studies of low-dimensional boron-based nanostructures. Appl. Sci. 2019, 9, 1019. [CrossRef]

4. Kunii, S.; Kasuya, T.; Kadowaki, K.; Date, M.; Woods, S.B. Electron tunneling into superconducting YB 6 . Solid State Commun. 1984, 52, 659-661. [CrossRef]

5. Zhang, H.; Tang, J.; Zhang, Q.; Zhao, G.; Yang, G.; Zhang, J.; Zhou, O.; Qin, L.-C. Field emission of electrons from single LaB 6 nanowire. Adv. Mater. 2006, 18, 87-91. [CrossRef]

6. Jang, H.; Friemel, G.; Ollivier, J.; Dukhnenko, A.V.; Shitsevalova, N.Y.; Filipov, V.B.; Keimer, B.; Inosov, D.S. Intense low-energy ferromagnetic fluctuations in the antiferromagnetic heavy-fermion metal CeB 6 . Nat. Mater. 2014, 13, 682-687. [CrossRef]

7. Pohlit, M.; Rößler, S.; Ohno, Y.; Ohno, H.; Von Molnár, S.; Fisk, Z.; Müller, J.; Wirth, S. Evidence for ferromagnetic clusters in the colossal-magnetoresistance material $\mathrm{EuB}_{6}$. Phys. Rev. Lett. 2018, 120, 257201. [CrossRef] [PubMed]

8. Li, L.; Sun, K.; Kurdak, C.; Allen, J.W. Emergent mystery in the Kondo insulator samarium hexaboride. Nat. Rev. Phys. 2020, 2, 463-479. [CrossRef]

9. Zhang, H.; Zhang, Q.; Tang, J.; Qin, L.C. Single-crystalline LaB 6 nanowires. J. Am. Chem. Soc. 2005, 127, 2862-2863. [CrossRef] 
10. Zhang, H.; Zhang, Q.; Tang, J.; Qin, L.C. Single-crystalline CeB 6 nanowires. J. Am. Chem. Soc. 2005, 127, 8002-8003. [CrossRef]

11. Zhang, H.; Zhang, Q.; Zhao, G.; Tang, J.; Zhou, O.; Qin, L.C. Single-crystalline GdB 6 nanowire field emitters. J. Am. Chem. Soc. 2005, 127, 13120-13121. [CrossRef]

12. Xu, J.; Zhao, Y.; Zou, C. Self-catalyst growth of $\mathrm{LaB}_{6}$ nanowires and nanotubes. Chem. Phys. Lett. 2006, 423, 138-142. [CrossRef]

13. Zou, C.Y.; Zhao, Y.M.; Xu, J.Q. Synthesis of single-crystalline CeB 6 nanowires. J. Cryst. Growth 2006, 291, 112-116. [CrossRef]

14. Ding, Q.; Zhao, Y.; Xu, J.; Zou, C. Large-scale synthesis of neodymium hexaboride nanowires by self-catalyst. Solid State Commun. 2007, 141, 53-56. [CrossRef]

15. Xu, J.; Chen, X.; Zhao, Y.; Zou, C.; Ding, Q.; Jian, J. Self-catalyst growth of EuB 6 nanowires and nanotubes. J. Cryst. Growth 2007, 303, 466-471. [CrossRef]

16. Xu, J.Q.; Zhao, Y.M.; Shi, Z.D.; Zou, C.Y.; Ding, Q.W. Single-crystalline SmB 6 nanowires. J. Cryst. Growth 2008, $310,3443-3447$. [CrossRef]

17. Brewer, J.R.; Deo, N.; Wang, Y.M.; Cheung, C.L. Lanthanum hexaboride nanoobelisks. Chem. Mater. 2007, $19,6379-6381$. [CrossRef]

18. Wang, G.; Brewer, J.R.; Chan, J.Y.; Diercks, D.R.; Cheung, C.L. Morphological evolution of neodymium boride nanostructure growth by chemical vapor deposition. J. Phys. Chem. C 2009, 113, 10446-10451. [CrossRef]

19. Brewer, J.R.; Jacobberger, R.M.; Diercks, D.R.; Cheung, C.L. Rare earth hexaboride nanowires: General synthetic design and analysis using atom probe tomography. Chem. Mater. 2011, 23, 2606-2610. [CrossRef]

20. Chi, M.; Zhao, Y.; Fan, Q.; Han, W. The synthesis of $\operatorname{PrB}_{6}$ nanowires and nanotubes by the self-catalyzed method. Ceram. Int. 2014, 40, 8921-8924. [CrossRef]

21. Zhang, H.; Tang, J.; Yuan, J.; Ma, J.; Shinya, N.; Nakajima, K.; Murakami, H.; Ohkubo, T.; Qin, L.-C. Nanostructured LaB 6 field emitter with lowest apical work function. Nano Lett. 2010, 10, 3539-3544. [CrossRef] [PubMed]

22. Xu, J.; Chen, X.; Zhao, Y.; Zou, C.; Ding, Q. Single-crystalline $\operatorname{PrB}_{6}$ nanowires and their field-emission properties. Nanotechnology 2007, 18, 115621. [CrossRef]

23. Xu, J.Q.; Zhao, Y.M.; Zhang, Q.Y. Enhanced electron field emission from single-crystalline LaB 6 nanowires with ambient temperature. J. Appl. Phys. 2008, 104, 124306. [CrossRef]

24. Xu, J.Q.; Zhao, Y.M.; Ji, X.H.; Zhang, Q.; Lau, S.P. Growth of single-crystalline $\mathrm{SmB}_{6}$ nanowires and their temperature-dependent electron field emission. J. Phys. D Appl. Phys. 2009, 42, 135403. [CrossRef]

25. Zhang, Q.Y.; Xu, J.Q.; Zhao, Y.M.; Ji, X.H.; Lau, S.P. Fabrication of large-scale single-crystalline PrB 6 nanorods and their temperature-dependent electron field emission. Adv. Funct. Mater. 2009, 19, 742-747. [CrossRef]

26. Xu, J.; Hou, G.; Li, H.; Zhai, T.; Dong, B.; Yan, H.; Wang, Y.; Yu, B.; Bando, Y.; Golberg, D. Fabrication of vertically aligned single-crystalline lanthanum hexaboride nanowire arrays and investigation of their field emission. NPG Asia Mater. 2013, 5, e53. [CrossRef]

27. Xu, J.; Hou, G.; Mori, T.; Li, H.; Wang, Y.; Chang, Y.; Luo, Y.; Yu, B.; Ma, Y.; Zhai, T. Excellent field-emission performances of neodymium hexaboride $\left(\mathrm{NdB}_{6}\right)$ nanoneedles with ultra-low work functions. Adv. Funct. Mater. 2013, 23, 5038-5048. [CrossRef]

28. Li, Q.; Zhang, H.; Chen, J.; Zhao, Y.; Han, W.; Fan, Q.; Liang, Z.; Liu, X.; Kuang, Q. Single-crystalline La ${ }_{x} \mathrm{Nd}_{1-x} \mathrm{~B}_{6}$ nanowires: Synthesis, characterization and field emission performance. J. Mater. Chem. C 2015, 3, 7476-7482. [CrossRef]

29. Zhang, H.; Tang, J.; Zhang, L.; An, B.; Qin, L.C. Atomic force microscopy measurement of the Young's modulus and hardness of single $\mathrm{LaB}_{6}$ nanowires. Appl. Phys. Lett. 2008, 92, 173121. [CrossRef]

30. Hossain, F.M.; Riley, D.P.; Murch, G.E. Ab initio calculations of the electronic structure and bonding characteristics of LaB6. Phys. Rev. B 2005, 72, 235101. [CrossRef]

31. Liu, H.; Zhang, X.; Ning, S.; Xiao, Y.; Zhang, J. The electronic structure and work functions of single crystal LaB 6 typical crystal surfaces. Vacuum 2017, 143, 245-250. [CrossRef]

32. Neupane, M.; Xu, S.Y.; Alidoust, N.; Bian, G.; Kim, D.J.; Liu, C.; Belopolski, I.; Chang, T.-R.; Jeng, H.-T.; Durakiewicz, T.; et al. Non-Kondo-like electronic structure in the correlated rare-earth hexaboride YbB6. Phys. Rev. Lett. 2015, 114, 016403. [CrossRef] [PubMed]

33. Dzero, M.; Xia, J.; Galitski, V.; Coleman, P. Topological kondo insulators. Annu. Rev. Condens. Matter Phys. 2016, 7, 249-280. [CrossRef]

34. Gan, H.B.; Peng, L.X.; Yang, X.; Tian, Y.; Xu, N.S.; Chen, J.; Liu, F.; Deng, S.Z. A moderate synthesis route of 5.6 mA-current $\mathrm{LaB}_{6}$ nanowire film with recoverable emission performance towards cold cathode electron source applications. RSC Adv. 2017, 7, 24848-24855. [CrossRef]

35. Fu, C.; Xu, J.; Chang, Y.; Wang, Q.; Wang, Y.; Yu, B.; Guo, P.; Xu, J.; Sun, H.; Luo, Y.; et al. Flexible three-dimensional CeB 6 nanowire arrays and excellent field emission emitters. J. Alloys Compd. 2017, 729, 997-1003. [CrossRef]

36. Han, W.; Zhao, Y.; Fan, Q.; Li, Q. Preparation and growth mechanism of one-dimensional NdB 6 nanostructures: Nanobelts, nanoawls, and nanotubes. RSC Adv. 2016, 6, 41891-41896. [CrossRef]

37. Han, W.; Zhang, H.; Chen, J.; Zhao, Y.; Fan, Q.; Li, Q.; Liu, X.; Lin, X. Single-crystalline La $\operatorname{Pr}_{1-x} B_{6}$ nanoawls: Synthesis, characterization and growth mechanism. Ceram. Int. 2016, 42, 6236-6243. [CrossRef]

38. Gan, H.; Ye, B.; Zhang, T.; Xu, N.; He, H.; Deng, S.; Liu, F. A controllable solid-source CVD route to prepare topological Kondo insulator $\mathrm{SmB}_{6}$ nanobelt and nanowire arrays with high activation energy. Cryst. Growth Des. 2019, 19, 845-853. [CrossRef] 
39. Zhou, Y.; Peng, Y.H.; Yin, Y.L.; Zhou, W.C.; Zhou, F.; Liu, C.; Liu, G.T.; Sun, L.F.; Tang, D.S. Large-scale synthesis and electrical transport properties of single-crystalline $\mathrm{SmB}_{6}$ nanowires. J. Phys. D Appl. Phys. 2016, 49, 265302. [CrossRef]

40. Selvan, R.K.; Genish, I.; Perelshtein, I.; Calderon Moreno, J.M.; Gedanken, A. Single step, low-temperature synthesis of submicronsized rare earth hexaborides. J. Phys. Chem. C 2008, 112, 1795-1802. [CrossRef]

41. Zhang, M.; Yuan, L.; Wang, X.; Fan, H.; Wang, X.; Wu, X.; Wang, H.; Qian, Y. A low-temperature route for the synthesis of nanocrystalline $\mathrm{LaB}_{6}$. J. Solid State Chem. 2008, 181, 294-297. [CrossRef]

42. Zhang, M.; Wang, X.; Zhang, X.; Wang, P.; Xiong, S.; Shi, L.; Qian, Y. Direct low-temperature synthesis of $R B_{6}(\mathrm{R}=\mathrm{Ce}, \mathrm{Pr}, \mathrm{Nd})$ nanocubes and nanoparticles. J. Solid State Chem. 2009, 182, 3098-3104. [CrossRef]

43. Zhang, M.; Jia, Y.; Xu, G.; Wang, P.; Wang, X.; Xiong, S.; Wang, X.; Qian, Y. Mg-assisted autoclave synthesis of RB 6 (R = Sm, Eu, $\mathrm{Gd}$, and $\mathrm{Tb}$ ) submicron cubes and $\mathrm{SmB}_{6}$ submicron rods. Eur. J. Inorg. Chem. 2010, 8, 1289-1294. [CrossRef]

44. Pol, V.G.; Pol, S.V.; Gedanken, A. Dry autoclaving for the nanofabrication of sulfides, selenides, borides, phosphides, nitrides, carbides, and oxides. Adv. Mater. 2011, 23, 1179-1190. [CrossRef]

45. Wang, L.; Xu, L.; Ju, Z.; Qian, Y. A versatile route for the convenient synthesis of rare-earth and alkaline-earth hexaborides at mild temperatures. CrystEngComm 2010, 12, 3923-3928. [CrossRef]

46. Chen, B.; Yang, L.; Heng, H.; Chen, J.; Zhang, L.; Xu, L.; Qian, Y.; Yang, J. Additive-assisted synthesis of boride, carbide, and nitride micro/nanocrystals. J. Solid State Chem. 2012, 194, 219-224. [CrossRef]

47. Zhou, L.; Yang, L.; Shao, L.; Chen, B.; Meng, F.; Qian, Y.; Xu, L. General fabrication of boride, carbide, and nitride nanocrystals via a metal-hydrolysis-assisted process. Inorg. Chem. 2017, 56, 2440-2447. [CrossRef] [PubMed]

48. Kanakala, R.; Rojas-George, G.; Graeve, O.A. Unique preparation of hexaboride nanocubes: A first example of boride formation by combustion synthesis. J. Am. Ceram. Soc. 2010, 93, 3136-3141. [CrossRef]

49. Kanakala, R.; Escudero, R.; Rojas-George, G.; Ramisetty, M.; Graeve, O.A. Mechanisms of combustion synthesis and magnetic response of high-surface-area hexaboride compounds. ACS Appl. Mater. Inter. 2011, 3, 1093-1100. [CrossRef]

50. Portehault, D.; Devi, S.; Beaunier, P.; Gervais, C.; Giordano, C.; Sanchez, C.; Antonietti, M. A general solution route toward metal boride nanocrystals. Angew. Chem. Int. Ed. 2011, 50, 3262-3265. [CrossRef]

51. Liu, X.; Gong, Y. Molten salt synthesis of samarium borides with controllable stoichiometry and morphology. J. Alloys Compd. 2021, 867, 159174. [CrossRef]

52. Wang, Z.; Han, W.; Kuang, Q.; Fan, Q.; Zhao, Y. Low-temperature synthesis of $\mathrm{CeB}_{6}$ nanowires and nanoparticles as feasible lithium-ion anode materials. Adv. Powder Tech. 2020, 31, 595-603. [CrossRef]

53. Han, W.; Qiu, Y.; Zhao, Y.; Zhang, H.; Chen, J.; Sun, S.; Lan, L.; Fan, Q.; Li, Q. Low-temperature synthesis and electronic transport of topological insulator $\mathrm{SmB}_{6}$ nanowires. CrystEngComm 2016, 18, 7934-7939. [CrossRef]

54. Wang, Z.; Han, W.; Fan, Q.; Zhao, Y. High-pressure growth and magnetic and electrical properties of EuB 6 nanowires. Phys. Status Solidi (RRL) Rapid Res. Lett. 2021, 15, 2100249. [CrossRef]

55. Han, W.; Wang, Z.; Li, Q.; Liu, H.; Fan, Q.; Dong, Y.; Kuang, Q.; Zhao, Y. Autoclave growth, magnetic, and optical properties of $\mathrm{GdB}_{6}$ nanowires. J. Solid State Chem. 2017, 256, 53-59. [CrossRef]

56. Han, W.; Wang, Z.; Li, Q.; Lian, X.; Liu, X.; Fan, Q.; Zhao, Y. Semiconductor-insulator transition in a YbB 6 nanowire with boron vacancy. J. Solid State Chem. 2018, 262, 244-250. [CrossRef]

57. Wang, Z.; Han, W.; Zhang, J.; Fan, Q.H.; Zhao, Y.M. Superconducting YB 6 nanowires. Ceram. Int. 2021, 47, 23788-23793. [CrossRef]

58. Kong, L.J.; Zhou, Y.; Liu, S.; Lin, Z.; Zhang, L.; Lin, F.; Tang, D.S.; Wu, H.C.; Liu, J.F.; Lu, H.Z.; et al. Spin-polarized surface state transport in a topological Kondo insulator $\mathrm{SmB}_{6}$ nanowire. Phys. Rev. B 2017, 95, 235410. [CrossRef]

59. Zhou, L.; Ye, B.C.; Gan, H.B.; Tang, J.Y.; Chen, P.B.; Du, Z.Z.; Tian, Y.; Deng, S.Z.; Guo, G.P.; Lu, H.Z.; et al. Surface-induced positive planar Hall effect in topological Kondo insulator $\mathrm{SmB}_{6}$ microribbons. Phys. Rev. B 2019, 99, 155424. [CrossRef]

60. He, X.S.; Gan, H.B.; Du, Z.Z.; Ye, B.C.; Zhou, L.; Tian, Y.; Deng, S.Z.; Guo, G.P.; Lu, H.Z.; Liu, F.; et al. Magnetoresistance anomaly in topological Kondo insulator $\mathrm{SmB}_{6}$ nanowires with strong surface magnetism. Adv. Sci. 2018, 5, 1700753. [CrossRef]

61. Kong, L.J.; Zhou, Y.; Song, H.D.; Yu, D.P.; Liao, Z.M. Magnetoresistance hysteresis in topological Kondo insulator SmB 6 nanowire. Chin. Phys. B 2019, 28, 107501. [CrossRef]

62. Gan, H.; Ye, B.; Zhou, L.; Zhang, T.; Tian, Y.; Deng, S.; He, H.; Liu, F. Controllable synthesis of Gd-doped SmB 6 nanobelt arrays for modulating their surface transport behaviors. Mater. Today Nano 2020, 12, 100097. [CrossRef]

63. Kang, C.J.; Denlinger, J.D.; Allen, J.W.; Min, C.H.; Reinert, F.; Kang, B.Y. Electronic structure of YbB 6 : Is it a topological insulator or not? Phys. Rev. Lett. 2016, 116, 116401. [CrossRef] [PubMed]

64. Zhou, Y.; Kim, D.J.; Rosa, P.F.S.; Wu, Q.; Guo, J.; Zhang, S.; Wang, Z.; Kang, D.; Zhang, C.; Yi, W.; et al. Pressure-induced quantum phase transitions in a $\mathrm{YbB}_{6}$ single crystal. Phys. Rev. B 2015, 92, 241118. [CrossRef]

65. Munarriz, J.; Robinson, P.J.; Alexandrova, A.N. Towards a single chemical model for understanding lanthanide hexaborides. Angew. Chem. 2020, 132, 22873-22878. [CrossRef]

66. Zhang, H.; Tang, J.; Yuan, J.S.; Yamauchi, Y.; Suzuki, T.T.; Shinya, N.; Nakajima, K.; Qin, L.C. An ultrabright and monochromatic electron point source made of $\mathrm{LaB}_{6}$ nanowire. Nat. Nanotech. 2016, 11, 273. [CrossRef]

67. Zhang, H.; Jimbo, Y.; Niwata, A.; Ikeda, A.; Yasuhara, A.; Ovidiu, C.; Kimoto, K.; Kasaya, T.; Miyazaki, H.T.; Tsujii, N.; et al. High-endurance micro-engineered $\mathrm{LaB}_{6}$ nanowire electron source for high-resolution electron microscopy. Nat. Nanotechnol. 2021, 1-6. [CrossRef] 
68. Tang, S.; Tang, J.; Wu, Y.M.; Chen, Y.-H.; Uzuhashi, J.; Ohkubo, T.; Qin, L.-C. Stable field-emission from a CeB 6 nanoneedle point electron source. Nanoscale 2021, 13, 17156-17161. [CrossRef] [PubMed]

69. Zhou, Y.; Lai, J.W.; Kong, L.J.; Ma, J.C.; Lin, Z.L.; Lin, F.; Zhu, R.; Xu, J.; Huang, S.M.; Tang, D.S.; et al. Single crystalline SmB 6 nanowires for self-powered, broadband photodetectors covering mid-infrared. Appl. Phys. Lett. 2018, 112, 162106. [CrossRef]

70. Xue, Q.; Tian, Y.; Deng, S.Z.; Huang, Y.; Zhu, M.S.; Pei, Z.X.; Li, H.F.; Liu, F.; Zhi, C.Y. LaB 6 nanowires for supercapacitors. Mater. Today Energy 2018, 10, 28-33. [CrossRef]

71. Lee, S.; Stanev, V.; Zhang, X.; Stasak, D.; Flowers, J.; Higgins, J.S.; Dai, S.; Blum, T.; Pan, X.; Yakoveno, V.M.; et al. Perfect Andreev reflection due to the Klein paradox in a topological superconducting state. Nature 2019, 570, 344-348. [CrossRef] [PubMed]

72. Li, S. Salt-assisted chemical vapor deposition of two-dimensional transition metal dichalcogenides. iScience 2021, $24,103229$. [CrossRef] [PubMed] 